\title{
A experiência em África para as línguas de Helder e Coetzee
}

\section{Carolina Anglada ${ }^{1}$}

RESUMO: O presente ensaio aborda a relação que o escritor português Herberto Helder e o sul-africano J. M. Coetzee estabelecem com a linguagem, a partir de suas experiências em África. Ao comparar obras dos dois autores, objetiva-se perceber como as práticas e fatos decorrentes da permanência em África condicionam, no caso de Helder, seu método tradutório e, em Coetzee, o estatuto de indiscernibilidade e impropriedade que a língua assume em sua obra.

ABSTRACT: The present essay focuses on the relationship that the Portuguese writer Herbert Helder and the South African J.M. Coetzee establish with language considering their experiences in Africa. By comparing works of these two authors, the objective is to understand how the practices and facts arising from their living in Africa affect their writing, in Helder's case, his method of translation, in Coetzee's, the status of indiscernibility and impropriety that language takes in his work.

PALAVRAS-CHAVE: Linguagem; Literatura Comparada; Herberto Helder; J.M. Coetzee KEYWORDS: Language; Comparative Literature; Herberto Helder; J.M. Coetzee

Herberto Helder, escritor português em atividade, entrega-se à escrita de maneira incessante, sem, no entanto, assentir com a participação pública requisitada pela mídia ${ }^{2}$ e pela academia. Autor de uma vasta obra poética, um livro de contos, outro que reúne ensaios, poemas, fragmentos e relatos, a autobiografia Apresentação do rosto e cinco publicações resultantes de suas incursões na tradução, Helder se mantém em pleno labor com a palavra, própria e alheia, alterando a tradição ao construir uma cartografia fracionada de textos espalhados no tempo e no espaço. ${ }^{3}$ Para ele, o poder da escrita é produzir uma tensão mais elementar do que aquela que se encontra subtraída da realidade. ${ }^{4}$

Menos recluso, mas ainda assim discreto se comparado a uma vasta gama de escritores contemporâneos cuja imagem está fundada pela mídia, o escritor sul-africano John Maxwell Coetzee adota, de forma geral, um estilo mais sugestivo do que prescritivo. Nascido em um continente marcado por abusos e conflitos, seria de se esperar um engajamento enérgico com a causa nacional, ainda que pela via da escolha da língua na qual se publicar originalmente. No entanto, é justamente contrariando essa

\footnotetext{
${ }^{1}$ Mestranda em Literaturas Modernas e Contemporâneas (UFMG). Email: angladacarolina@ gmail.com.

${ }^{2}$ São raras as entrevistas dadas pelo autor, sendo a autoentrevista elaborada para a revista Inimigo rumor, ironicamente, uma das mais comentadas.

${ }^{3}$ Por meio de suas incursões na tradução, Helder verte para o português poemas maias, astecas, ameríndios, dispondo página após página poemas do Antigo Egito, do Velho Testamento, seguidos por D.H. Lawrence, Michael Lowy etc. A matéria poética, transversal no tempo e no espaço, é também manifesta na antologia Eloi lelia doura.

${ }^{4}$ No fragmento "( a mão negra )", Helder escreve sobre o poder da escrita, que "produz uma tensão muito mais fundamental do que a realidade. É nessa tensão real criada em escrita que a realidade se faz. $\mathrm{O}$ ofuscante poder da escrita é possuir uma capacidade de persuasão e violentação de que a coisa real se encontra subtraída." (HELDER, 2006a, p. 54)
} 
expectativa que Coetzee assume uma das principais vertentes de sua obra, ao construir uma literatura mais universal do que propriamente nacional, trabalhando questões inerentes ao contexto pós-colonial de maneira pulverizada e subjetiva.

Diante de projetos literários e contextos notadamente díspares, podemos estabelecer, ainda assim, algumas consonâncias entre os dois escritores, que vão para além de suas semelhantes posturas reservadas. Elegendo a geografia como ponto primeiro a aproximá-los, tomo o relato de Herberto Helder no fragmento "(magia)", pertencente a Photomaton \& vox, sobre sua ida a África por ocasião de um filme "inspirado, baseado ou pretextado num texto" (HELDER, 2006a, p. 120) seu. A experiência decorrida na estadia no continente excede o motivo que o levou até lá. Após assistir ao filme, o escritor pressente que a película sobrepuja seu poema em diversos sentidos e proporções, e passa a atribuir ao texto uma falha: "um erro incorrigível" (2006a, p. 120) do próprio poema, da forma de dispor as palavras; erro aperfeiçoado pela eficácia do filme. O autor fala em ter sido "desapossado do lugar, do poema" (2006a, p. 121), uma vez que a força do escrito passa a existir no filme e, como numa tentativa de se resguardar, o escritor exclui o texto do conjunto das coisas pessoais.

Emerge nesse relato um problema de autoria. Assistir ao filme pretextado em seu poema faz o escritor se sentir "desapossado." Mas como poderia o poeta se proteger de tais abusos? Para além dos processos infinitos de intertextualidade a que estão submetidas as criações, no ambiente africano essa contaminação é radicalizada, sendo posta em questão a noção tradicional de propriedade.

A magia, enredada na matéria da autoria, é estendida na continuação da narrativa do mesmo fragmento. De uma incursão ao leste do país (cujo nome não é informado), o poeta relata que trouxera uma pequena máscara que só poderia ser tocada pelo feiticeiro que a fizera. A seguir, Helder evidencia a exemplaridade do caso ao mencionar que se trata de mais um evento de "autoridade legítima" (2006a, p. 121). Mesmo assim, ele não só viola a regra ao tocar a máscara como a torna "coisa sua." Ao mostrá-la para outros, eles não se detêm por muito tempo no objeto e mudam logo de assunto. Essa seria a razão para a máscara se imbuir, progressivamente, de energia. Energia capaz de provocar o acidente que a pessoa de Herberto Helder sofreu um dia após assistir ao filme, a setecentos quilômetros de distância da máscara que permanecia em casa. As quatro categorias de acontecimentos, isto é, poema, filme, máscara e desastre, estariam imbricadas em um mesmo sistema.

$\mathrm{Na}$ malha da descrição desse acontecimento levado a cabo pelos poderes mágicos da máscara, está enredado o mecanismo do próprio fazer poético. Helder 
anuncia que o poema deveria ser destruído - o poema, como princípio de toda a construção/destruição que se segue. Para criar, é preciso destruir, não se limitar ao que precede. A formação de uma língua pessoal, em Herberto Helder, portanto, é paradoxal. Nos versos do quinto poema de "Poemacto", o poeta escreve sobre esses dualismos presentes na criação:

\author{
Que é preciso recriar o criar, meu Deus, ser truculento \\ Ser simples e não o ser \\ $[\ldots]$ \\ Criar é delicado. \\ Criar é uma grande brutalidade. \\ Porque eu sou feliz. Durmo \\ na obra. (HELDER, 2006b, p. 117-119)
}

Bem como é preciso destruir para criar, em Helder há uma convergência entre ler e escrever. Embevecido com a magia vivida em África, o escritor aplica a ciência indisciplinada da autoria dispersa em suas traduções. O termo usado pelo poeta português para assinalar essas obras aponta para a singularidade de seu método; seus últimos três livros vêm com a legenda "poemas mudados para o português" (grifo nosso). A palavra muda de língua. Pelo teor da inscrição, parece que algo além do idioma estará diferente. Um dos motivos é que a leitura de Helder dos textos a serem mudados estabelece uma relação determinante com a sua poética e com os seus fundamentos, e não com o projeto do outro, como é tradicional na tradução. Para esta reflexão, é válido recorrermos ao fragmento "(o bebedor nocturno)", no qual Helder (2006a, p. 68-69) esclarece o seu método:

\begin{abstract}
Quanto a mim, não sei línguas. Trata-se da minha vantagem. Permiteme verter poesia do Antigo Egipto, desconhecendo o idioma, para o português. [...]Versão indirecta, diz alguém. Recriação pessoal, diz alguém. [...] Não digo nada, eu. Se dissesse, diria: prazer. O meu prazer é assim: deambulatório, ao acaso, por súbito amor, projectivo. Não tenho o direito de garantir que esses textos são traduções. O meu labor consiste em fazer com que eu próprio ajuste cada vez mais ao meu gosto pessoal o clima geral do poema já português: a temperatura da viagem, a velocidade do ritmo, a saturação atmosférica do vocábulo, a pressão do adjectivo sobre o substantivo.
\end{abstract}

A incompatibilidade entre as línguas, portanto, seria um a priori, que todo trabalho de tradução deveria levar em conta, não havendo, então, "infidelidade" quanto ao original. "A regra de ouro é: liberdade" (HELDER, 2006a, p. 68).

Assim, Helder disponibiliza todo um repertório de textos poéticos silenciados pela tradição. Sob o encontro com formas arcaicas e nomes que mantêm relações 
particulares com as coisas, traduzir é revitalizar o vocabulário e abrir uma linguagem sem as impregnações contemporâneas que cerceiam seu significado e atuação. Uma palavra que tenha presença, uma vez que a palavra do cotidiano está divorciada do corpo. É essa palavra buscada que pode alterar a língua-mãe, contribuindo para a formação de uma língua pessoal. O contexto de enunciação africano apresenta-se então como um lugar vocalmente múltiplo; propício para o contato com a palavra selvagem, que nada mais é do que uma palavra ainda não domesticada.

Ao mudar para o português o breve poema "Divisa", um dos quatro poemas árabes incluídos em $O$ bebedor nocturno, Herberto Helder dispõe os dois versos que atribui a Al-Moutanabbi - poeta que viveu de 915 a 965, tido como um dos mais importantes de língua árabe - da seguinte forma: "Conhecem-me os cavalos e a noite e os desertos/traiçoeiros e a guerra e as feridas e o papel e a pena" (HELDER, 2010, p. 101).

No primeiro verso do poema, sequenciam-se nomes consonantes com a liberdade e com a natureza: "cavalos", "noite” e "desertos." Logo em seguida, por uso do enjambement, soma-se o adjetivo "traiçoeiros," qualificador dos desertos, e uma série de outros nomes que se revelam de uma ordem diversa de conhecimento do eu: "guerras", "feridas", "papel” e "pena." O título do poema, "Divisa”, já anuncia a cisão entre o primeiro e segundo verso, sendo o segundo metalinguístico, pois a pena e o papel apresentam-se como uma regra, uma obrigação. Se tomarmos a tradução do termo enjambement como "encavalgamento," podemos ler o poema, por um lado, como o montar do primeiro verso, natural ao homem, no segundo, representativo das instâncias que restringem sua liberdade e, por isso mesmo, como a só possível desconexão entre os limites do que liberta e do que aprisiona o homem.

O pensador italiano Giorgio Agamben, no texto-ensaio que dá nome a sua obra Ideia da prosa, se propõe a refletir justamente sobre o que diferencia a prosa da poesia. Agamben aponta o enjambement - não o ritmo, não a quantidade, nem o número de sílabas - como marca distintiva da oposição entre o limite métrico e o sintático, próprio, portanto, da poesia:

O enjambement exibe uma não coincidência e uma desconexão entre o elemento métrico e o elemento sintático, entre o ritmo sonoro e o sentido, como se contrariamente a um preconceito muito generalizado, que vê nela o lugar de um encontro, de uma perfeita consonância entre som e sentido, a poesia vivesse, pelo contrário, apenas da sua íntima discórdia. (AGAMBEN, 2012, p. 31) 
Se Helder afirma não saber línguas, podemos desconfiar que o enjambement não seja próprio ao poema original. Em uma versão disponível no site Adab, destinado a poetas árabes, o poema, que aparece sem título, é colocado da seguinte forma, já traduzido para o inglês: "The desert knows me well, the night and the mounted men/The battle and the sword, the paper and the pen" (AL-MUTANABBI, [s. d.]).

Ainda que seja impossível saber, ao certo, qual a fonte de Helder, o poema em inglês apresenta-se de maneira diversa do poema mudado para o português. Mesmo com a cadência, Helder não privilegiou a rima, como faz a versão em inglês, pareando "men" e "pen." O único verbo é posto logo no início para depois se construir a cadeia de nomes, embora, em inglês, o que abra o poema seja “o deserto." Há ainda a inversão de termos e a ocultação do advérbio "bem," na versão helderiana, mas o que de fato sobressai entre as diferenças de ambas as versões é o enjambement. Interrompendo a significação do que vinha sendo construído no primeiro verso com o adjetivo "traiçoeiros", que abre o segundo verso, Helder realiza o que Agamben classifica como “desconexão entre o elemento métrico e o elemento sintático" (AGAMBEN, 2012, p. 31), partindo rumo a uma transgressão de unidade e de identidade, e fortalecendo o sentido de cisão.

No cerne das versões de Herberto Helder estão, pois, mestiçagens oriundas de uma matéria poética difundida nas diversas culturas e das transformações realizadas pelo tradutor para adubar a língua-mãe. Um outro poema, que inaugura a seção "Poemas arábico-andaluzes" do mesmo livro, introduz novamente o teor metalinguístico. Com o título de "A leitura", o poema aborda a tarefa do leitor: "Meus olhos resgatam o que está preso na página:/O branco do branco e o preto do preto" (HELDER, 2010, p. 107).

O poema atribuído a Ben Ammar, que viveu em Sevilha na segunda metade dos anos 1000, sugere que há algo além do signo impresso nas páginas a ser recuperado. Tanto o que não se diz está preso no não dito quanto o dito está limitado ao que se diz. O branco, isto é, o não escrito, o espaço vazio, resguarda significados que estão para além da ausência da página. $\mathrm{O}$ mesmo se passa com o preto, isto é, com o grafado, o impresso. Não é o nome que oprime a ideia; cada um se oprime por suas próprias formas. Como num jogo de xadrez, em que o espaço do branco e preto intercalados pode se estender ao infinito, a leitura de Ammar cujo processo está baseado na relação entre os dois elementos que podem se reorganizar a cada nova leitura, por isso mesmo, também beira o infindo. 
Ao recorrer a textos de épocas antigas, como os dois poemas anteriores, Herberto Helder erige a palavra em uma potência desencontrada das significações cotidianas e viciadas. Servem-lhe bibliografias exóticas, culturas e formas de saber heterogêneas, metáforas e imagens que desorientam as fontes de um problema, assim como a Jorge Luis Borges, o dito escritor enciclopédico. Helder põe em evidência a instabilidade que afeta toda a relação de propriedade com o saber e a cultura. Tendo a palavra ao seu dispor, ainda que confesse não saber línguas, o escritor verte-a do inglês, francês, italiano ou espanhol para "construir o poema português pelo sentido emocional, mental, linguístico" (HELDER, 2006a, p. 69). A língua-mãe, expressivamente beneficiada pelo contato com a língua outra, pode valer-se de novas imagens. Há a necessidade de diferentes mundos translinguísticos para que surjam novas línguas natais, como José Gil (1988) salienta em Fernando Pessoa ou a metafísica das sensações a respeito da heteronímia pessoana.

O excerto encabeçado por um título cujo significado muito orienta a poética de Helder, "(antropofagias)”, insinua as possíveis articulações entre criação e destruição, canibalismo e festividade, liberdade e ritual. Conclui-se no mesmo fragmento: "o homem é uma linguagem, e o tema é a agonia da linguagem" (2006a, p. 128). Por essa via, aproximo agora o escritor sul-africano J.M. Coetzee, que, na escolha do inglês como língua de seus romances, provoca um efeito de estranhamento, como se representasse um estrangeiro em sua própria terra.

O escritor carrega em seu nome próprio as marcas de uma língua implacável. "Coetzee" é certamente um dos sobrenomes mais reconhecidamente africâneres ${ }^{5}$ e, portanto, mais estigmatizados na história da África do Sul. É a palavra que impõe a memória de uma culpa ancestral, por ser herdeira de privilégios negados aos negros, e não só isso, representativa de quem pensou o apartheid essencialmente em termos de exclusão. Esse dilema, ainda que Coetzee o ignorasse, lhe seria relembrado por seu nome, ou faria seus próximos relembrarem.

Assim sendo, a língua para Coetzee não é uma pátria, como o é para Fernando Pessoa. A maior parte dos escritores africâneres escreve originalmente na língua que é uma espécie de holandês com forte influência do inglês, do alemão e do malaioportuguês. Sobretudo na geração de 60 do século XX, ressaltava-se a importância de se publicar em africâner, num gesto de valorização da língua criada no sul de África, apesar de sua inerente raiz europeia. Mas Coetzee permanece publicando em inglês. Há,

\footnotetext{
5 "Africâner" é um termo cunhado a partir da década de 1930 para designar os diversos grupos de descendentes dos primeiros colonizadores holandeses e franceses.
} 
por certo, uma indiscernibilidade de qual língua o representaria. Se por um lado o inglês encena a posição do colonizador, o africâner o inseriria na "tribo branca" de África.

Em Desonra, o personagem David Lurie, professor acadêmico de Línguas Modernas na Cidade do Cabo, é desapossado de sua ocupação na Universidade pelo fato de sua aluna, Melanie (melanina, numa óbvia alusão à cor), denunciar abuso. A impropriedade da língua é apresentada desde o momento em que, coagido a se confessar publicamente, Lurie alega que o necessário é apenas se declarar culpado, sendo impossível averiguar se, caso confessasse os pormenores e pedisse perdão, estaria sendo sincero ou apenas cumprindo o protocolo para sua salvação: "Perante este tribunal secular, me declarei culpado, uma declaração secular. Essa declaração deveria bastar. Arrependimento não tem nada a ver nem com uma coisa, nem com outra. Arrependimento pertence a outro mundo, a outro universo de discurso" (COETZEE, 2011, p. 71).

Coetzee traz à discussão as práticas posteriores aos regimes colonizadores e de abuso em que o explorador é obrigado a se posicionar publicamente e garantir arrependimento. No diálogo com a comissão formada para averiguar o seu caso e responder tanto ao público quanto à comunidade acadêmica, Lurie pressente uma demanda por humilhações e remediações que deem conta do escândalo.

Quando decide ficar recluso na fazenda onde a filha, Lucy, habita, ela é estuprada por três homens, sendo um deles o sobrinho de Petrus, o homem negro que a ajuda na fazenda. Lurie insiste para que a filha saia de lá, viaje, mas Lucy acredita que não adiantaria. É o preço que ela paga por ser branca em uma região de negros, e os estupradores seriam os cobradores dessa dívida. Lurie, por sua vez, sente-se ineficiente. A língua, as línguas, de nada valem num território como esse: "Ele fala italiano, fala francês, mas italiano e francês de nada valem na África negra. Está desamparado, um alvo fácil..." (COETZEE, 2011, p.115).

O silêncio de Lurie, mesmo vivendo a reversibilidade do abuso, tanto como opressor quanto como familiar de uma vítima, e o silêncio de Coetzee diante das acusações que sofre por sua obra, em muito se aproximam da visão de Helder, expressa no fragmento "(ramificações autobiográficas)", que se comporta como uma retificação sobre o próprio engajamento político da literatura, esperado pela crítica e pelo leitor que toma conhecimento da obra em perspectiva com um contexto determinado: "Fala-se para estar só, ser contra os outros, limitar a invasão do mundo - dessas ruas e casas, dessa população de funcionários angélicos. Não me venham com inocências nem sabedorias" (HELDER, 2006a, p. 26). 
Nesse caso, não há desvelamento na literatura de ambos que não de um enigma. Coetzee não resolve o problema do abuso em Desonra; longe disso, lança o paradoxo, abordando a complexidade por enredos indiretos, sem particularizar o político ou o privado. Aprendendo a se desvencilhar da censura do apartheid, sua escrita foi se tornando um jogo: ora revela, ora dissimula.

A instauração de um enigma fica ainda mais evidente em $A$ vida dos animais. Convidado a proferir uma palestra para as Tanner Lectures na Universidade de Princeton, Coetzee se vale, mais uma vez, de sua personagem ficcional, Elizabeth Costello, tida pela crítica como alter ego do escritor. O que se esperava ser um ensaio filosófico teve como forma a ficção. Essa prática acabou se repetindo outras vezes e hoje é uma das estratégias mais habituais de Coetzee para se expressar sobre tópicos diversos, elidindo a forma tradicional do ensaio ao se valer do distanciamento construído por personagens que discutem o tema em questão no interior da narrativa. No jogo da escrita, objetividade e subjetividade, realidade e ficção, palavra e coisa estão entranhados, borrando-se seus limites consensuais.

O tema do animal, em evidência e efervescência hoje, provoca acaloradas discussões, inclusive no ambiente acadêmico, assumindo diferentes faces de acordo com a área. A própria Elizabeth Costello parece ter ciência disso, quando afirma: "Quero encontrar um jeito de falar com meus semelhantes humanos que seja calmo e não inflamado, filosófico e não polêmico, que traga iluminação e não divisão [...]" (COETZEE, 2002, p. 27). A maneira idealizada por ela seria falar com o coração, e não com a razão, como teriam feito Descartes, Tomás de Aquino, Platão, Kant etc.

\begin{abstract}
Cogito ergo sum [...] é uma fórmula que sempre me incomodou. Pressupõe que um ser vivo que não faz o que ele chama de pensar é, de alguma forma, um ser de segunda classe. Ao ato de pensar, a cogitação, oponho a plenitude, a corporalidade, a sensação de ser - não uma consciência de si mesmo como uma espécie de fantasmagórica máquina raciocinante pensando pensamentos, mas, ao contrário, a sensação - uma sensação pesadamente afetiva - de ser um corpo com membros que têm uma extensão no espaço, de se estar vivo no mundo [...] (COETZEE, 2002, p. 41)
\end{abstract}

O coração seria o órgão por excelência capaz de simpatizar com o outro e partilhar o ser do outro. É a "imaginação simpatizante" presente sobretudo na poesia, a responsável pela generosidade com a alteridade, sem que o saber se reparta como nas faculdades mentais. No poema, respeita-se o singular (o homem, as teorias do conhecimento, as coisas) e o anônimo (o animal, por exemplo). Helder pode ser aqui retomado, pelo trecho de "(guião)", no qual concede à poesia exclusividade para explicar as diversas matérias e teorias do mundo: "Mitologia, linguística, psicologia, 
ideologia não esclarecem o poema. O poema é que, acidentalmente, pode esclarecê-las. [...] A escrita é a aventura de conduzir a realidade até ao enigma, e propor-lhe decifrações problemáticas (enigmáticas)" (HELDER, 2006, p. 136-137).

Ter vivido em África, portanto, se revela nos dois escritores como experiência com os limites da linguagem, ainda que o resultado literário em J.M. Coetzee e Herberto Helder sejam, naturalmente, diferentes. O escritor sul-africano, vivenciando uma relação de estranhamento com a língua, herdada da tradição, mantém-se no inglês, mas altera as formas de se portar diante de determinados temas, assumindo a ficção e a escrita poética como formas de linguagem que mais se aproximam de um posicionamento ético para com a história, para com a alteridade e, sobretudo, para com o seu projeto literário. Herberto Helder, por sua vez, embevecido com a antropofagia mágica, sente-se livre para se apropriar de poemas, enigmas, canções arcaicas e, de certa forma, alterar a tradição por meio do seu par, a tradução. Ambos, conscientes da dúvida, da impossibilidade e da impropriedade que envolve a assunção da palavra, arriscam-se em suas literaturas.

\section{Referências:}

AGAMBEN, Giorgio. Ideia da prosa. Tradução de João Barrento. Belo Horizonte: Autêntica, 2012.

AL-MUTANABBI. [The desert knows me well]. [s.d.] Disponível em: $<$ http://www.adab.com/en/modules.php?name=Sh3er\&doWhat=ssd\&shid=25>. Acesso em: 06 maio 2013.

COETZEE, J.M. Desonra. Tradução de José Rubens Siqueira. São Paulo: Companhia das Letras, 2011.

COETZEE, J.M. A vida dos animais. Tradução de José Rubens Siqueira. São Paulo: Companhia das Letras, 2002.

GIL, José. Fernando Pessoa ou a metafísica das sensações. Lisboa: Relógio d'água, 1988.

HELDER, Herberto. O bebedor nocturno. Lisboa: Assírio \& Alvim, 2010.

HELDER, Herberto. Photomaton \& vox. Lisboa: Assírio \& Alvim, 2006a.

HELDER, Herberto. Ou o poema contínuo. São Paulo: A Girafa, 2006b. 